NASA/TM-2003-211987

\title{
Interplay Between Thin Film Ferroelectric Composition, Microstructure, and Microwave Phase Shifter Performance
}

\author{
Carl H. Mueller
}

Analex Corporation, Brook Park, Ohio

Frederick W. Van Keuls

Ohio Aerospace Institute, Brook Park, Ohio

Robert R. Romanofsky, Samuel A. Alterovitz, and Félix A. Miranda Glenn Research Center, Cleveland, Ohio 
Since its founding, NASA has been dedicated to the advancement of aeronautics and space science. The NASA Scientific and Technical Information (STI) Program Office plays a key part in helping NASA maintain this important role.

The NASA STI Program Office is operated by Langley Research Center, the Lead Center for NASA's scientific and technical information. The NASA STI Program Office provides access to the NASA STI Database, the largest collection of aeronautical and space science STI in the world. The Program Office is also NASA's institutional mechanism for disseminating the results of its research and development activities. These results are published by NASA in the NASA STI Report Series, which includes the following report types:

- $\quad$ TECHNICAL PUBLICATION. Reports of completed research or a major significant phase of research that present the results of NASA programs and include extensive data or theoretical analysis. Includes compilations of significant scientific and technical data and information deemed to be of continuing reference value. NASA's counterpart of peerreviewed formal professional papers but has less stringent limitations on manuscript length and extent of graphic presentations.

- TECHNICAL MEMORANDUM. Scientific and technical findings that are preliminary or of specialized interest, e.g., quick release reports, working papers, and bibliographies that contain minimal annotation. Does not contain extensive analysis.

- CONTRACTOR REPORT. Scientific and technical findings by NASA-sponsored contractors and grantees.
- CONFERENCE PUBLICATION. Collected papers from scientific and technical conferences, symposia, seminars, or other meetings sponsored or cosponsored by NASA.

- SPECIAL PUBLICATION. Scientific, technical, or historical information from NASA programs, projects, and missions, often concerned with subjects having substantial public interest.

- TECHNICAL TRANSLATION. Englishlanguage translations of foreign scientific and technical material pertinent to NASA's mission.

Specialized services that complement the STI Program Office's diverse offerings include creating custom thesauri, building customized databases, organizing and publishing research results ... even providing videos.

For more information about the NASA STI Program Office, see the following:

- Access the NASA STI Program Home Page at http://www.sti.nasa.gov

- E-mail your question via the Internet to help@sti.nasa.gov

- Fax your question to the NASA Access Help Desk at 301-621-0134

- Telephone the NASA Access Help Desk at 301-621-0390

- Write to:

NASA Access Help Desk

NASA Center for AeroSpace Information 7121 Standard Drive

Hanover, MD 21076 
NASA/TM-2003-211987

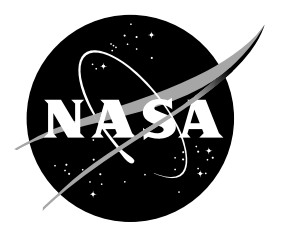

\section{Interplay Between Thin Film Ferroelectric Composition, Microstructure, and Microwave Phase Shifter Performance}

Carl H. Mueller

Analex Corporation, Brook Park, Ohio

Frederick W. Van Keuls

Ohio Aerospace Institute, Brook Park, Ohio

Robert R. Romanofsky, Samuel A. Alterovitz, and Félix A. Miranda

Glenn Research Center, Cleveland, Ohio

Prepared for the

13th International Symposium on Integrated Ferroelectrics

sponsored by the Ultrasonics, Ferroelectrics, and Frequency Control Society

Nara, Japan, May 28-June 1, 2002

National Aeronautics and

Space Administration

Glenn Research Center 
Available from

NASA Center for Aerospace Information 7121 Standard Drive

Hanover, MD 21076
National Technical Information Service 5285 Port Royal Road Springfield, VA 22100

Available electronically at http://gltrs.grc.nasa.gov 


\title{
INTERPLAY BETWEEN THIN FILM FERROELECTRIC COMPOSITION, MICROSTRUCTURE, AND MICROWAVE PHASE SHIFTER PERFORMANCE
}

\author{
Carl H. Mueller \\ Analex Corporation \\ Brook Park, Ohio 44142 \\ Frederick W. Van Keuls \\ Ohio Aerospace Institute \\ Brook Park, Ohio 44142 \\ Robert R. Romanofsky, Samuel A. Alterovitz, and Félix A. Miranda
National Aeronautics and Space Administration
Glenn Research Center
Cleveland, Ohio 44135
}

\begin{abstract}
One of the keys to successfully incorporating ferroelectric films into Ku-band (12 to $18 \mathrm{GHz}$ ) phase shifters is to establish the composition, microstructure and thickness required to meet the tuning needs, and tailor the film properties to meet these needs. Optimal performance is obtained when the film composition and device design are such that the device performance is limited by odd mode dielectric losses, and these losses are minimized as much as possible while still maintaining adequate tunability. The parameters required to maintain device performance will vary slightly depending on composition, but we can conclude that the best tuning-to-loss figures of merit (K-factor) are obtained when there is minimal variation between the in-plane and out-of-plane lattice parameters, and the fullwidth half maximum values of the BSTO (002) peaks are less than approximately $0.04^{\circ}$. We have observed that for phase shifters in which the ferroelectric crystalline quality and thickness are almost identical, higher losses are observed in films with higher $\mathrm{Ba} / \mathrm{Sr}$ ratios. The best performance was observed in phase shifters with $\mathrm{Ba}: \mathrm{Sr}=30: 70$. The superiority of this composition was attributed to several interacting factors: the Ba:Sr ratio was such that the Curie temperature $(180 \mathrm{~K})$ was far removed from room temperature, the crystalline quality of the film was excellent, and there was virtually no difference between the in-plane and out-of-plane lattice parameters of the film.
\end{abstract}

\section{INTRODUCTION}

The development of thin film ferroelectric devices for tunable phase shifters for electronically beam steerable antennas has remained an attractive yet elusive goal for several years [1, 2]. As the need for higher data rate, highly robust satellite communication links becomes increasingly apparent, the demand for a novel, electronically steerable antenna technology that fulfills the requirements of a Ku-band (12 to $18 \mathrm{GHz})$ and higher frequency links in a costeffective manner becomes equally apparent [3]. Ferroelectric thin films offer considerable potential to fill this niche, but the technology is considered by most antenna designers to be immature. One of the difficulties involved in optimizing ferroelectric phase shifters is to understand the complex relationships between intrinsic material properties, extrinsic defects, and phase shifter design. Accurate microwave designs rely upon exact knowledge of material properties, and this is not the case with tunable Barium Strontium Titanate (BSTO) films. The effect of microstructure, $\mathrm{Ba} / \mathrm{Sr}$ composition, and film thickness on microwave performance, is still inadequate.

The goal of this paper is to correlate thin film microstructure with the Ku-band performance of coupled microstrip phase shifters. The phase shifter is designed for a beam-steerable reflectarray antenna. The key attributes desired from this phase shifter are that it must supply at least $180^{\circ}$ of phase shift (in the transmission mode), be sufficiently small so that each phase shifter and its accompanying radiating element occupy an area no larger than $\lambda_{0} / 2 \times \lambda_{0} / 2$, and the insertion loss is as low as possible. To achieve this goal, we have studied the performance of BSTO phase shifters with various $\mathrm{Ba}: \mathrm{Sr}$ ratios. In this study, we examined films with $\mathrm{Ba}: \mathrm{Sr}$ ratios ranging from 0 to 100 percent $\mathrm{Ba}$. The effect of lattice parameter (in-plane and out-of-plane) and crystal quality were also correlated with device performance. 


\section{EXPERIMENTAL}

The BSTO films were purchased from a commercial vendor. The films were deposited on two-inch $\mathrm{LaAlO}_{3}$ wafers using a pulsed laser deposition system. The microstructure properties of the films were monitored using high resolution x-ray diffractometry (HRXRD) and optical ellipsometry. X-ray diffraction measurements were taken using a Phillips PW 3720 High Resolution X-Ray Diffractometer. Measurements were taken in the double-axis mode, with a four-reflection Ge (220) channel-cut crystal placed between the x-ray tube and sample. No beam conditioners were placed between sample and detector. Symmetric omega-two theta $(\Omega-2 \theta)$ rocking curve scans were taken about the BSTO (002), and asymmetric scans were taken about the (103) and (013) diffraction peaks. The full-width half-maximum (FWHM) values of the (002) peaks were taken from the symmetric scans, and the inplane and out-of-plane lattice parameters were obtained from the asymmetric scans [4]. For all of the wafers, XRD data was taken from four different locations (center, 7, 14, and $21 \mathrm{~mm}$ radially, in different directions) on the wafer, and the average value of the four measurements is reported.

Optical ellipsometry measurements ( $\psi$ and $\Delta$ ) were taken using a "J.A. Woollam Co., Inc." rotating compensator spectroscopic ellipsometer model M-2000L at an angle of incidence of $65^{\circ}$ at 800 wavelengths, in the range 245 to $900 \mathrm{~nm}$. The analysis was restricted to the 400 to $900 \mathrm{~nm}$, corresponding to the range over which absorption was minimal. The dielectric functions of the films were modeled using a Cauchy function for the refractive index and an exponential function for the extinction coefficient [5], as commonly found for low absorption materials [6, 7]. The top roughness layer was modeled as an EMA (Bruggeman Effective Medium Approximation) [8] mixture of the Cauchy modeled film and a variable fraction of voids. The variables in the least squares fit were: film and surface overlayer thicknesses, void fraction in the surface overlayer and five dielectric function parameters. The analysis was complicated by the presence of numerous twins in the samples, which cause light to be scattered in a nonspecular manner. A quantitative value for the non-specularity called the "depolarization factor" was measured with this rotating compensator ellipsometer. To minimize the influence of the depolarization caused by the twins, several measurements were taken at different spots (up to 4 spots) around the center of the 2 in. wafer. Although it was not possible to completely eliminate the depolarization, we limited ourselves to results with depolarization factors below 20 percent.

The microwave performance of the films was measured using an eight-element coupled microstrip phase shifter design. The details of the design have been published elsewhere [9]. Briefly, the phase shifter design is based on a series of coupled microstriplines of length $(=1)$ and separation $(=\mathrm{s})$ patterned over the ferroelectric films. For each section, 1 and s were 400 and $7.5 \mu \mathrm{m}$, respectively, and the phase shifter was comprised of eight sections. The maximum coupled voltage occurs when the coupled sections are a quarter wavelength long (i.e., $\beta 1=90^{\circ}$ ). The devices tested in this study operated in the 15 to $17 \mathrm{GHz}$ range. Bias up to $400 \mathrm{~V}$ is applied to the sections via printed bias tees consisting of a quarter-wave radial stub in series with a very high impedance quarter-wave microstrip. The strip widths are chosen so as to approximate a $50 \Omega$ characteristic impedance. A schematic diagram of the test circuit is shown in figure 1. Phase shift, insertion loss, and reflection coefficient were measured using a HP $8510 \mathrm{C}$ automatic network analyzer.

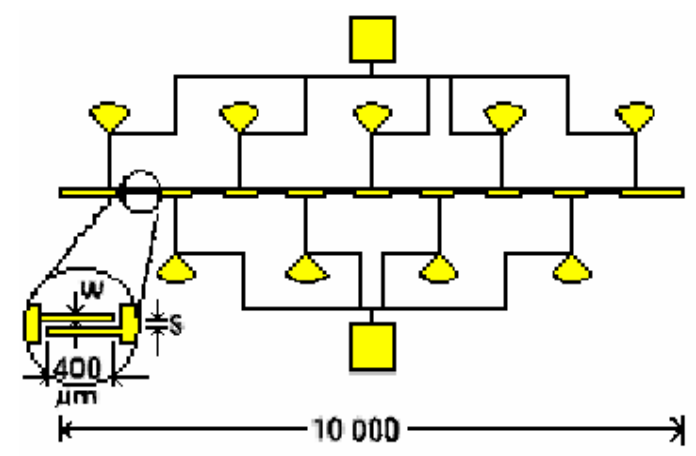

Figure 1. Schematic of ferroelectric eight-element coupled microstrip phase shifter. 


\section{RESULTS}

Optical ellipsometry measurements analyzed over the range 400 to $900 \mathrm{~nm}$ show that the thickness of the films varied from 300 to $370 \mathrm{~nm}$ (except pure BTO). For films with $\mathrm{Ba} \leq 0.70$, the refractive indices at $632.8 \mathrm{~nm}$ varied from 2.36 to 2.40 (see figure 2). These values are close to that of bulk, single-crystal $\mathrm{SrTiO}_{3}$ (2.39) [10, 11], but relatively very high for thin films. The refractive indexes of BSTO films in the literature were found to vary considerably with the film growth method $[10,12]$. In general, we expect that a lower refractive index will indicate a

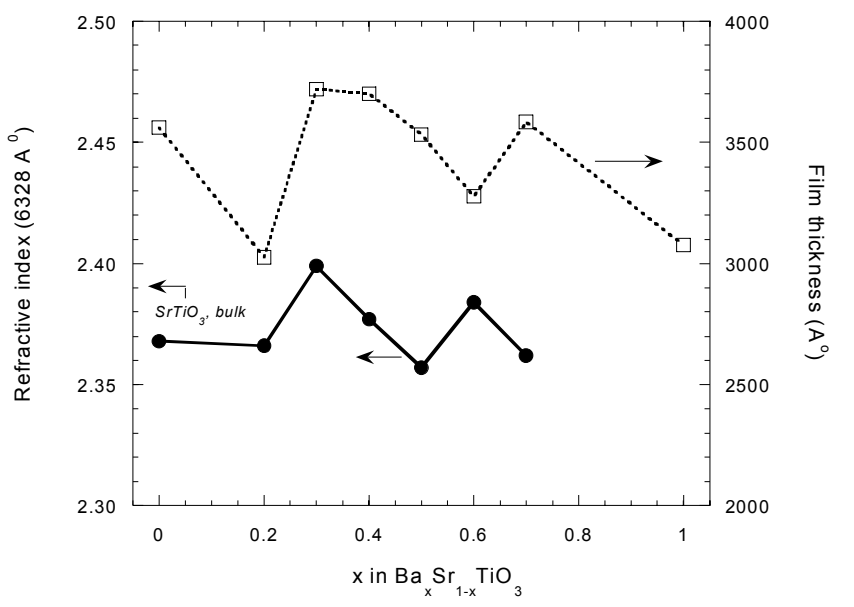

Figure 2. Refractive index and film thickness of $\mathrm{BSTO} / \mathrm{LAO}$ films, as a function of Ba content.

lower film quality, as the change of the refractive index versus the Ba:Sr ratio is much less than the change in the refractive index versus film quality. However, in this case the changes in the refractive index were very small, and ellipsometry indicates that all films are in general of good quality. The small difference in film quality is masked by the small, but still present influence of the twins on the final results.

HRXRD revealed that the crystalline quality of the film, as well as the in-plane versus out-of-plane lattice parameters, were most readily controlled for films with $0.20 \leq \mathrm{Ba} \leq 0.50$. The lattice mismatch decreases as the $\mathrm{Ba}$ content decreases; the lattice mismatch between LAO and STO is 3.6 percent, and the mismatch between LAO and BSTO (Ba:Sr $=50: 50)$ is 4.5 percent. Figure 3 demonstrates almost identical in-plane and out-of-plane lattice parameters for BSTO films with $0.20 \leq \mathrm{Ba} \leq 0.40$. HRXRD scans of the BSTO (002) peak also demonstrate high crystalline quality (as shown by the narrow full-width half-maximum values (FWHM)) for films with $0.20 \leq \mathrm{Ba} \leq 0.50$ (figure 4). At Ba contents $\geq 0.60$, there was clearly a decline in film crystalline quality. For the set of films with Ba $\leq 0.50$, the FWHM values were in the range 0.025 to 0.040 , which is equivalent or better than the best reported values for BSTO/LAO films. For films with $\mathrm{Ba}$ contents $\leq 0.50$, the film crystalline quality was similar and uniformly high. We believe that for phase shifters made from these films, deviations in device performance due to differences in film quality were negligible. Differences in device performance were most significantly impacted by the $\mathrm{Ba} / \mathrm{Sr}$ content and phase shifter design.

The phase shift and insertion loss behavior of the coupled microstrip phase shifters as a function of de voltage, for devices in which the Ba content varies from 0.00 to 0.60 , is shown in figures 5 to 8 . 


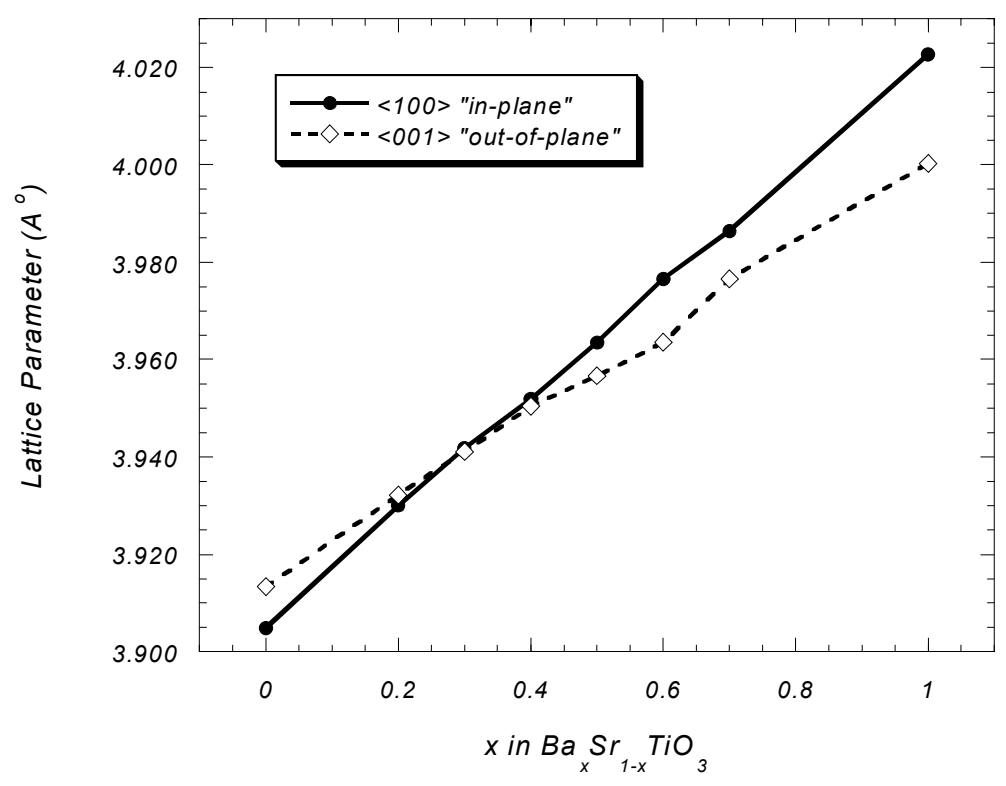

Figure 3. In-plane and out-of-plane lattice parameters BSTO films on $\mathrm{LaAlO}_{3}$ substrates, as a function of Ba:Sr film composition.

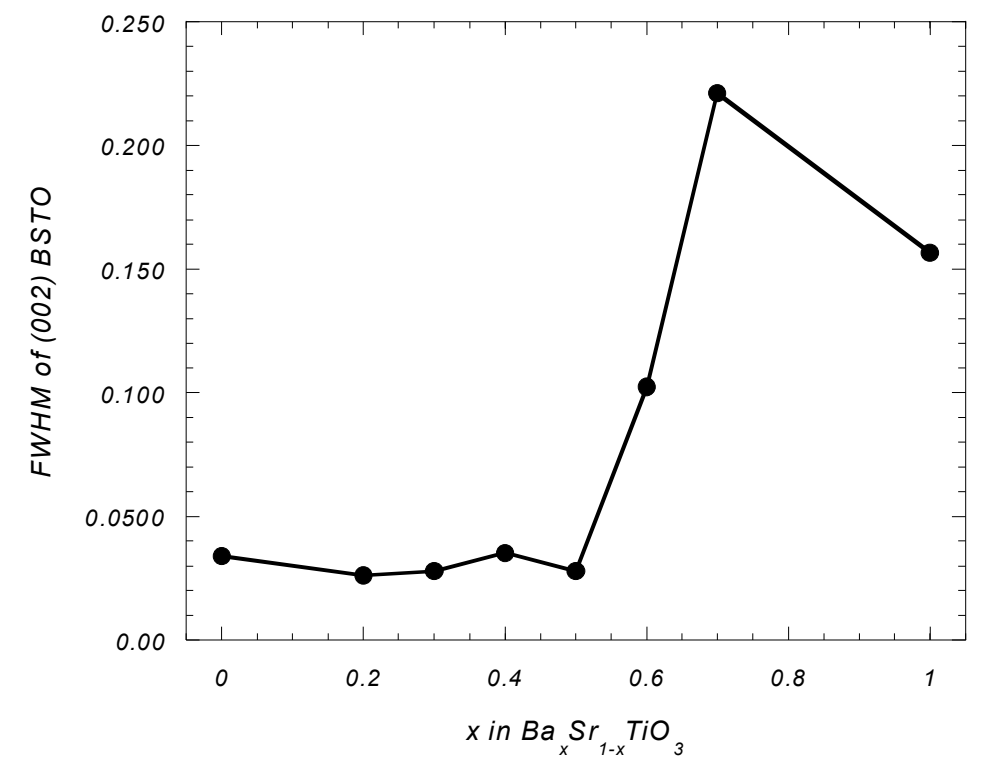

Figure 4. FWHM values of 3000 to $3700 \AA$ thick BSTO films on $\mathrm{LaAlO}_{3}$ substrates, as a function of Ba:Sr film composition. The FWHM values are minimal for $\mathrm{Ba}$ compositions $0.20 \leq \mathrm{Ba} \leq 0.50$. 


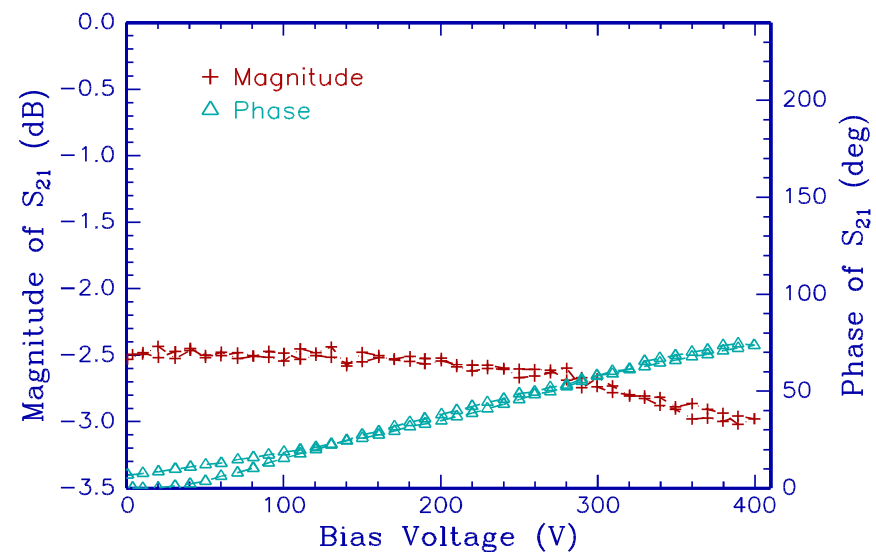

Figure 5. Phase shift of $\mathrm{S}_{21}$ and insertion loss versus applied dc bias of $\mathrm{SrTiO}_{3} / \mathrm{LaAlO}_{3}$ coupled microstrip phase shifter. Frequency $=16.8 \mathrm{GHz}$.

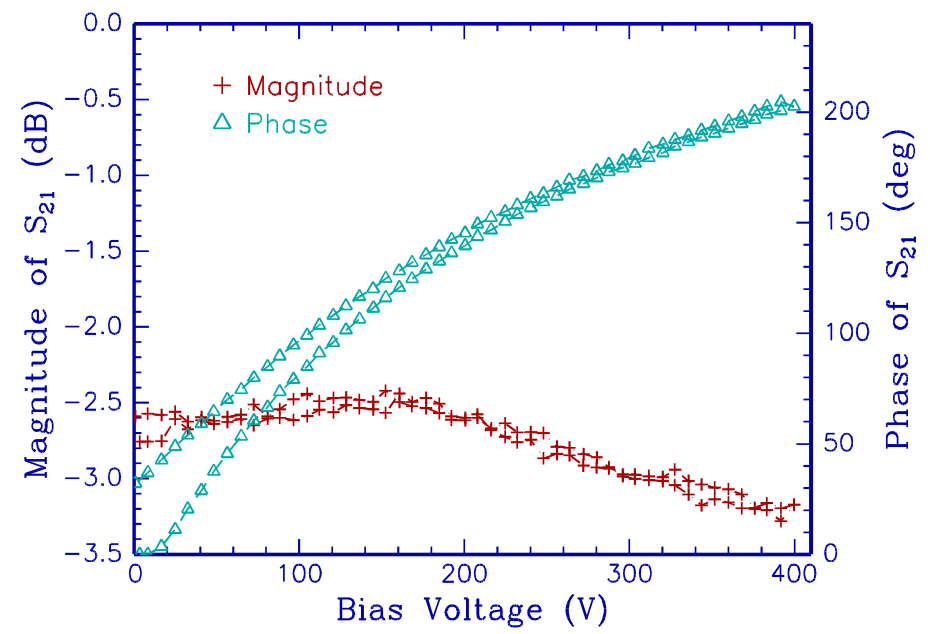

Figure 6. Phase shift of $S_{21}$ and insertion loss versus dc bias of $\left(\mathrm{Ba}_{0.3} \mathrm{Sr}_{0.7}\right) \mathrm{TiO}_{3} / \mathrm{LaAlO}_{3}$ coupled microstrip phase shifter.

Frequency $=15.5 \mathrm{GHz}$. 


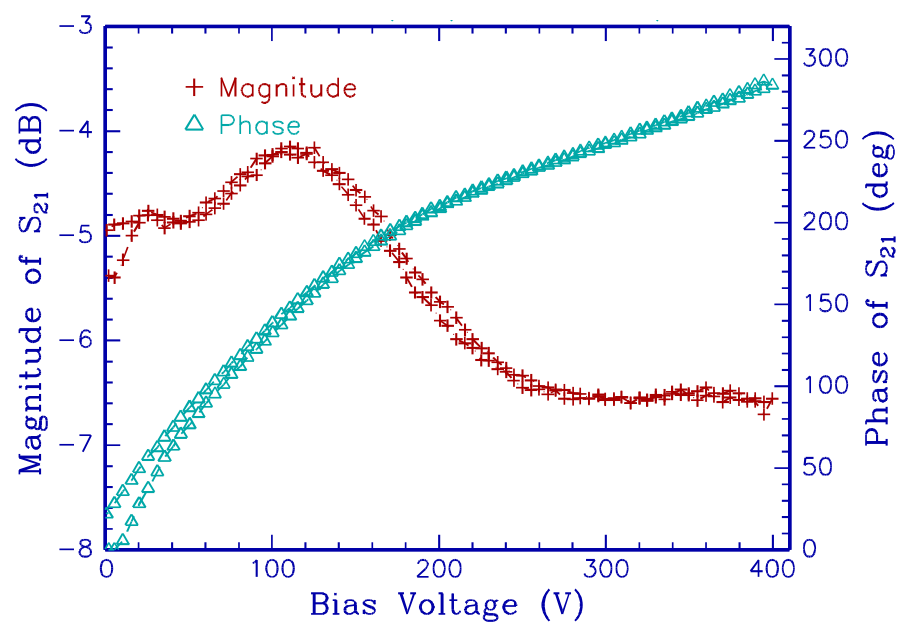

Figure 7. Phase shift of $\mathrm{S}_{21}$ and insertion loss versus dc bias of $\left(\mathrm{Ba}_{0.40} \mathrm{Sr}_{0.60}\right) \mathrm{TiO}_{3} / \mathrm{LaAlO}_{3}$ coupled microstrip phase shifter. Frequency $=15.8 \mathrm{GHz}$.

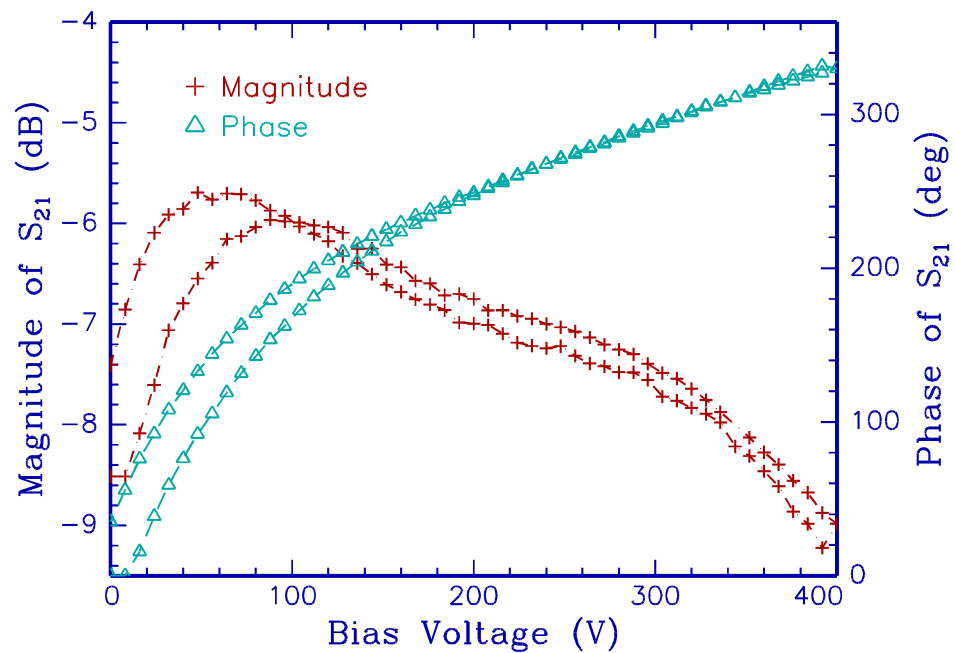

Figure 8. Phase shift of $\mathrm{S}_{21}$ and insertion loss versus dc bias of $\left(\mathrm{Ba}_{0.60} \mathrm{Sr}_{0.40}\right) \mathrm{TiO}_{3} / \mathrm{LaAlO}_{3}$ coupled microstrip phase shifter. Frequency $=16.25 \mathrm{GHz}$.

\section{DISCUSSION}

From the HR-XRD data, we observe that the crystalline quality of the films, as measured by the FWHM values, is high for films with $\mathrm{Ba} \leq 0.50$. At higher Ba contents, the film quality is inferior. The ellipsometry data showed that the refractive indices of the films were very similar to that of single crystal STO, indicating that the films were excellent by thin film standards. However, the ellipsometric data was not as accurate as is normally the case with this technique due to the presence of twins, which masked the small differences in the film quality. Another feature of the films is that there is a systematic change in film strain. For $\mathrm{Ba}<0.30$, the out-of-plane lattice parameter is larger than the in-plane lattice parameter, and for higher Ba contents the in-plane lattice parameter becomes larger. This trend was reported previously by Gim et al. [13] but the composition at which the crossover occurred was 
slightly different. It is possible that the exact composition at which the in-plane and out-of-plane lattice parameters are equivalent may be dependent on the deposition parameters.

The microwave phase shifter data clearly shows that the Ba:Sr composition has a major impact on the tunability and insertion loss. For films in the range $\mathrm{Ba}=0.00$ to 0.30 , there is an increase in phase shift with increasing $\mathrm{Ba}$ content, and little change in the $0 \mathrm{~V}$ insertion loss. The increase in tunability with higher $\mathrm{Ba}$ contents is attributed to progressively higher Curie temperatures. As the Curie temperature increases, the room temperature $\varepsilon_{\mathrm{r}}$ also increases, which leads to a higher tunable range. The lack of variation in insertion loss at $0 \mathrm{~V}$ bias voltages is attributed to the dominance of odd-mode dielectric losses [14] for films in this composition range. As the dc voltage level is increased, there is a slight increase in insertion losses, which is attributed to in-band resonances. For all compositions, low frequency $(1 \mathrm{MHz})$ data indicated that $\tan \delta$ of the film decreased with increasing dc bias voltage, thus it is unlikely that the higher insertion losses of the phase shifters with increasing bias voltage is due to ferroelectric film loss. Reducing the film $\varepsilon_{\mathrm{r}}$ and restricting the tunable range of the phase shifter minimizes the impact of this resonance on device insertion loss.

Devices for which the $\mathrm{Ba}$ content is in the range $0.40 \leq \mathrm{Ba} \leq 0.60$ demonstrate higher tunability than those with lower $\mathrm{Ba}$ contents, but also display substantially higher insertion losses. Phase shifters made from films with $\mathrm{Ba}: \mathrm{Sr}=$ 40:60 display very high tunability ( 280 degrees) and reasonably low unbiased insertion loss ( $\sim 5 \mathrm{~dB})$. However, as the bias level is increased above 160 volts, device-induced resonances cause a substantial increase in insertion loss. Thus the overall phase shift-to-insertion loss figure of merit for this film is considerably poorer than for devices using lower $\mathrm{Ba}$ content (i.e., $\mathrm{Ba}=0.30$ ) films. As the $\mathrm{Ba}$ content is increased to 0.50 and 0.60 , the magnitude of the unbiased insertion loss continues to increase, thus further reducing the tuning-to-loss figure of merit.

\section{CONCLUSIONS}

Our data indicates that one of the keys to successfully incorporating ferroelectric films in K-band phase shifters is to understand the composition and thickness required to meet the tuning needs, and select a composition based on these needs. Optimal performance is obtained when the film composition and device design are such that the device performance is limited by odd mode dielectric losses, and these losses are minimized as much as possible while still maintaining adequate tunability.

\section{REFERENCES}

1. F.W. Van Keuls, R.R. Romanofsky, D.Y. Bohman, M.D. Winters, F.A. Miranda, C.H. Mueller, R.E. Treece, T.V. Rivkin, and D. Galt, Appl. Phys. Lett. 71, p. 3075 (1997).

2. A.B. Kozyrev, V.N. Keis, G.A. Koepf, R.M. Yandrofski, O.I. Soldatenkov, K.A. Dudin, and D.P. Dovgan, Microelectronic Engineering 29, p. 257 (1995).

3. C.H. Mueller and F.A. Miranda, "Tunable Dielectric Materials and Devices for Broadband Wireless Communications," in Handbook of Thin Film Devices, Volume 5: Ferroelectric Film Devices. Edited by D.J. Taylor and M.H. Francombe, p. 113140 (Academic Press, New York, 2000).

4. D.K. Bowen and B.K. Tanner, High Resolution X-ray Diffractometry and Topography, p. 50 (Taylor and Francis, London, 1998).

5. E.D. Palik, Handbook of Optical Constants of Solids, p. 244 (Academic Press, New York, 1985).

6. K.S. Lau, J.A. Caulfield, and K.K. Gleason, J. Vac. Sci. Technol., A18, p. 2404 (2000).

7. D. Dalacu and L. Martinu, J. Vac. Sci. Technol., A17, p. 877 (1999).

8. D.A.G. Bruggeman, Ann. Phys. Leipzig 5, 637 (1935).

9. R.R. Romanofsky, J.T. Bernhard, F.W. Van Keuls, F.A. Miranda, G. Washington, and C. Canedy, IEEE Trans. Microwave Theory and Tech., 48, p. 2504 (2000).

10. S. Zollner, A.A. Demkov, R. Liu, P.L. Fejes, R.B. Gregory, J.A. Curless, Z. Yu, J. Ramdani, R. Droopad, T.E. Tiwald, J.N. Hilfiker and J.A. Woollam, J. Vac. Sci. Technol., B18, p. 2242 (2000).

11. G.E. Jellison Jr., L.A. Boatner, D.H. Lowndes, R.A. McKee, and M. Godbole, Applied Optics 33, p. 6053 (1994).

12. Y. Gao, A.H. Mueller, E.A. Irene, O. Aucielo, A. Krauss, and J.A. Schultz, J. Vac. Sci. Technol., A17, 1880 (1999), and references therein.

13. Y. Gim, T. Hudson, Y. Fan, C. Kwon, A.T. Findikoglu, B.J. Gibbons, B.H. Park, and Q.X. Jia, Appl. Phys. Lett 77, p. 1200 (2000).

14. E. Denlinger, IEEE Trans. Microwave Theory and Techn. 28, p. 513 (1980). 
Public reporting burden for this collection of information is estimated to average 1 hour per response, including the time for reviewing instructions, searching existing data sources, gathering and maintaining the data needed, and completing and reviewing the collection of information. Send comments regarding this burden estimate or any other aspect of this collection of information, including suggestions for reducing this burden, to Washington Headquarters Services, Directorate for Information Operations and Reports, 1215 Jefferson Davis Highway, Suite 1204, Arlington, VA 22202-4302, and to the Office of Management and Budget, Paperwork Reduction Project (0704-0188), Washington, DC 20503.

1. AGENCY USE ONLY (Leave blank) 2. REPORT DATE 3. REPORT TYPE AND DATES COVERED

4. TITLE AND SUBTITLE January 2003

Technical Memorandum

Interplay Between Thin Film Ferroelectric Composition, Microstructure, and Microwave Phase Shifter Performance

\section{AUTHOR(S)}

WU-755-08-0B-00

Carl H. Mueller, Frederick W. Van Keuls, Robert R. Romanofsky,

Samuel A. Alterovitz, and Félix A. Miranda

\section{PERFORMING ORGANIZATION NAME(S) AND ADDRESS(ES)}

National Aeronautics and Space Administration

John H. Glenn Research Center at Lewis Field

Cleveland, Ohio 44135-3191

\section{FUNDING NUMBERS}

\section{SPONSORING/MONITORING AGENCY NAME(S) AND ADDRESS(ES)}

National Aeronautics and Space Administration

Washington, DC 20546-0001

8. PERFORMING ORGANIZATION REPORT NUMBER

E-13426

\section{SUPPLEMENTARY NOTES}

Prepared for the 13th International Symposium on Integrated Ferroelectrics sponsored by the Ultrasonics, Ferroelectrics, and Frequency Control Society, Nara, Japan, May 28-June 1, 2002. Carl H. Mueller, Analex Corporation, Brook Park, Ohio 44142; Frederick W. Van Keuls, Ohio Aerospace Institute, Brook Park, Ohio 44142; Robert R. Romanofsky, Samuel A. Alterovitz, and Félix A. Miranda, NASA Glenn Research Center. Responsible person, Félix Miranda, organization code 5640, 216-433-6589.

Unclassified - Unlimited

Subject Categories: 17, 27, and 32

Distribution: Nonstandard

Available electronically at http://gltrs.grc.nasa.gov

This publication is available from the NASA Center for AeroSpace Information, 301-621-0390.

\section{ABSTRACT (Maximum 200 words)}

One of the keys to successfully incorporating ferroelectric films into Ku-band (12 to $18 \mathrm{GHz}$ ) phase shifters is to establish the composition, microstructure, and thickness required to meet the tuning needs, and tailor the film properties to meet these needs. Optimal performance is obtained when the film composition and device design are such that the device performance is limited by odd mode dielectric losses, and these losses are minimized as much as possible while still maintaining adequate tunability. The parameters required to maintain device performance will vary slightly depending on composition, but we can conclude that the best tuning-to-loss figures of merit (K-factor) are obtained when there is minimal variation between the in-plane and out-of-plane lattice parameters, and the full-width half maximum values of the BSTO (002) peaks are less than approximately $0.04^{\circ}$. We have observed that for phase shifters in which the ferroelectric crystalline quality and thickness are almost identical, higher losses are observed in films with higher Ba/Sr ratios. The best performance was observed in phase shifters with $\mathrm{Ba}: \mathrm{Sr}=30: 70$. The superiority of this composition was attributed to several interacting factors: the Ba:Sr ratio was such that the Curie temperature $(180 \mathrm{~K})$ was far removed from room temperature, the crystalline quality of the film was excellent, and there was virtually no difference between the inplane and out-of-plane lattice parameters of the film.

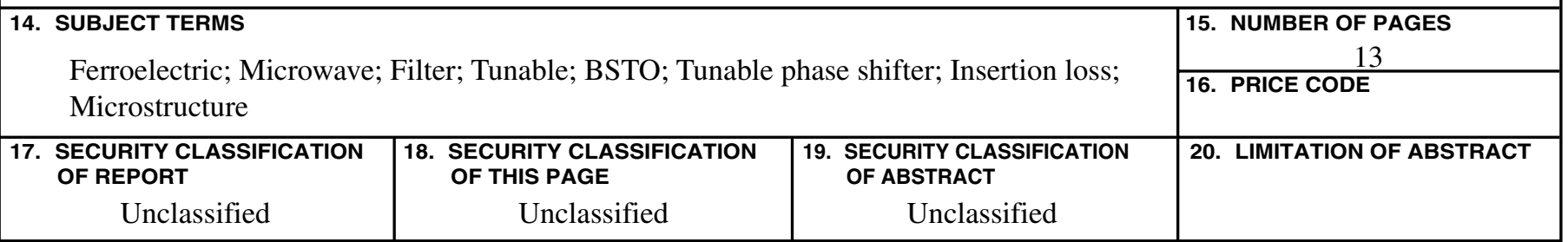

